\title{
Spatial population dynamics of a specialist aphid parasitoid, Lysiphlebus hirticornis Mackauer (Hymenoptera: Braconidae: Aphidiinae): evidence for philopatry and restricted dispersal
}

\author{
FN Nyabuga ${ }^{1,2}$, HD Loxdale ${ }^{1,2}$, DG Heckel ${ }^{2}$ and WW Weisser ${ }^{1}$ \\ ${ }^{1}$ Institute of Ecology, Friedrich Schiller University, Jena, Germany and ${ }^{2}$ Department of Entomology, Max Planck Institute for Chemical \\ Ecology, Jena, Germany
}

\begin{abstract}
Within insect communities, the population ecology of organisms representing higher trophic levels, for example, hymenopterous parasitoids, may be influenced by the structure of their insect hosts. Using microsatellite markers and ecological data, we investigated the population structure of the specialist braconid wasp parasitoid, Lysiphlebus hirticornis Mackauer attacking Metopeurum fuscoviride, a specialist aphid feeding on tansy, Tanacetum vulgare. Previous studies revealed that $M$. fuscoviride has a classic metapopulation structure with high subpopulation turnover. In this study, up to $100 \%$ of ramets within a host plant genet colonized by aphids were colonized by the parasitoid, yet plants with aphids but no parasitoids were also observed. Genetic differentiation measured by $F_{\mathrm{ST}}$, actual differentiation $(D)$ and relative differentiation $\left(G_{S T}\right)$ indicated highly structured parasitoid
\end{abstract}

population demes, with restricted gene flow among and between parasitoid subpopulations at the various sites. Interestingly, both field data and population assignment analysis showed that the parasitoid is highly philopatric. Thus, despite the frequent local extinctions of the aphid host, the parasitoid continuously exploits its aphid host and contributes to the demise of local aphid subpopulations, rather than spreading its genes over many aphid populations. $F_{\mathrm{ST}}$ values for the haplodiploid parasitoid were similar to those found in an independent study of the diploid aphid host, $M$. fuscoviride, hence supporting the view that an insect herbivore's population structure directly influences the ecology and genetics of the higher trophic level, in this case the wasp parasitoid.

Heredity (2010) 105, 433-442; doi:10.1038/hdy.2009.190; published online 27 January 2010

Keywords: L. hirticornis; M. fuscoviride; microsatellites; philopatry; isolation by distance; gene flow

\section{Introduction}

In recent years, a number of empirical studies have shown that metapopulation structure influences the genetic makeup of subpopulations of various organisms studied (for example, Bay et al., 2008; Orsini et al., 2008; Purrenhage et al., 2009), including aphids (Massonnet et al., 2002). General predictions about the genetic structure of metapopulations are difficult to make because of factors such as the population dynamics of local populations, their extinction rate, and the rate and distance of dispersal of the species under consideration (Harrison and Hastings, 1996; Pannell and Charlesworth, 2000). Broadly speaking, a metapopulation with frequent extinctions is expected to show lower overall genetic variability compared with an unstructured population of a similar organism with similar natural history, and subpopulations (colonies or demes) are more or less genetically differentiated depending on the balance between dispersal, colonization and extinction dynamics

Correspondence: FN Nyabuga, Institute of Ecology, Friedrich Schiller University, Dornburger Strasse 159, Jena, Thuringia 07743, Germany. E-mail: Franklin.Nyabuga@uni-jena.de

Received 18 May 2009; revised 18 December 2009; accepted 21 December 2009; published online 27 January 2010
(Pannell and Charlesworth, 2000). For example, in insect species with metapopulation dynamics, genetic differentiation between populations range from: (1) significant differences between almost all subpopulation pairs investigated, for example, the tansy aphid, Macrosiphoniella tanacetaria Kaltenbach (Hemiptera: Aphididae) (Massonnet et al., 2002); to (2) some level of genetic differentiation, such as that found in the wasp parasitoid, Hyposoter horticola Gravenhorst (Hymenoptera: Ichneumonidae), which attacks the Glanville fritillary butterfly, Melitaea cinxia L. (Lepidoptera: Nymphalidae) (Kankare et al., 2005); to (3) no genetic differentiation despite the existence of discrete subpopulations, for example, in the dung beetle, Aphodius fossor L. (Coleoptera: Scarabaeidae) (Roslin, 2001).

In spatially structured multitrophic systems such as those formed on plants by insect herbivores and their natural enemies, the population ecology of the higher trophic levels, for example, wasp parasitoids, may be influenced by the metapopulation structure of the host insect. However, few studies have to date estimated dispersal and genetic population structure at one or more trophic levels or analysed the influence of species interactions on metapopulation structure of one or more of the organisms involved (Cronin and Reeve, 2005). The few studies performed (for example, Johannesen and 
Seitz, 2003; Kankare et al., 2005; Anton et al., 2007) show that even though the herbivore host may have a distinct metapopulation structure, which also affects local survival of the parasitoid, the population genetic structure of the parasitoid can be very different.

The host-parasitoid system comprising the specialist wasp parasitoid, Lysiphlebus hirticornis Mackauer (Hymenoptera: Braconidae: Aphidiinae) attacking the specialist aphid, Metopeurum fuscoviride Stroyan (Hemiptera: Aphididae), which feeds exclusively on tansy, Tanacetum vulgare L. (family Asteracae), has a classic metapopulation structure (Weisser, 2000; Zheng et al., 2009). In a field study, Weisser (2000) reported frequent extinction events for the aphid, M. fuscoviride, and as a direct consequence, of the parasitoid L. hirticornis, at the level of tansy plants (=genets) and shoots (= ramets). At the local spatial scale (site), Weisser (2000) found that many tansy plants were not colonized by the aphid and many tansy genets with the aphid were not colonized by the parasitoid. He also reported a mean survival time of 3.1 and 4.8 weeks (mode $=1$ week) for aphids at the level of ramet and genet, respectively.

In support of the view that $M$. fuscoviride indeed shows a metapopualtion structure, Massonnet (2002), using six microsatellite markers on seven subpopulations (five from the Alsace region of France and two from Germany), reported high population differentiation: $F_{\mathrm{ST}}$ values ranged from 0.029 to 0.416 , and of the 21 pairwise $F_{\mathrm{ST}}$ comparisons performed, 18 were significant $(P<0.05)$.

L. hirticornis is a solitary parasitoid (that is, a single wasp develops from a single aphid host) that attacks aggregated aphids and will oviposit eggs in the same aphid colony until virtually all available hosts are parasitized or it becomes egg limited (Völkl, 1997). In addition, although winged, the adult parasitoids have a low dispersal ability (Rauch and Weisser, 2007), but this has not been tested directly using marked individualseither fluoresecent dyes or molecular DNA markers.

In this study, the population dynamics of L. hirticornis on hand-labeled tansy plants colonized by $M$. fuscoviride were surveyed, and parasitoid samples genotyped at 11 polymorphic microsatellite loci to assess the extent of L. hirticornis relative isolation and dispersal, the relationship of flight behaviour (or lack of it) to philopatry, and the effect of aphid host population structure (that is, that of $M$. fuscoviride, the second trophic level) on the genetic diversity and differentiation of the parasitoid, L. hirticornis (the third trophic level). To investigate these variables, we estimated the level of $L$. hirticornis colonization and dispersal on tansy genets colonized by M. fuscoviride, the population genetic differentiation of the parasitoid subpopulations and isolation by distance (IBD), analysed L. hirticornis for philopatric behaviour, and compared the population structure of this haplodiploid parasitoid with that of its diploid aphid host. Given the limited knowledge on the population genetic structure of the parasitoid in relation to that of its host, we tested the following hypotheses: (1) there is significant population genetic differentiation between local colonies of L. hirticornis; (2) as in the case of the host, there is no IBD in the parasitoid; and (3) the level of genetic differentiation in the parasitoid is as high as in the host aphids.

\section{Materials and methods}

\section{Study system}

Tansy is a perennial composite with bright yellow flowers native to Europe and Asia (Mitich, 1992). It grows mainly along river valleys, but also occurs in welldrained poor soils and on wastelands. It propagates by both sexual and asexual means and a single genet consists of numerous 'genetically identical' ramets produced by vegetative propagation.

The tansy aphid, M. fuscoviride, is a monophagous, holocyclic species (that is, with an autumnal/winter sexual phase involving the laying of cold-hardy eggs) that feeds exclusively on tansy (Massonnet, 2002). M. fuscoviride colonies are normally attended by ants, especially Lasius niger L. (Hymenoptera: Formicidae) (Mackauer and Völkl, 1993). From the aphid, ants obtain an important source of nutrients in the form of honeydew; in return, they act as guards, warding off predators and parasitoids (Völkl, 1997). The parasitoid L. hirticornis, is monophagous on M. fuscoviride (Starý, 1973) and is thought to mimic the cuticular hydrocarbons of its aphid host to evade ant attacks (Dettner and Liepert, 1994; Liepert, 1996).

\section{Field sites}

Parasitoid samples in the form of aphid mummies were collected between early June and late October, 2007 from 11 sites in and around Jena, Germany $\left(50^{\circ} 54^{\prime} \mathrm{N}, 11^{\circ} 35^{\prime}\right.$ E; Figure 1). The sites were composed of ruderal habitats (see Supplementary Appendix 1 for site location and description). The geographical positioning system was used to estimate distances between sampling sites, the furthest points being Göschwitz-Bhf and Dornburg-Bhf, $\sim 15 \mathrm{~km}$ apart.

\section{Field surveys and population sampling}

Genets at all sites were visited and inspected for M. fuscoviride every 10 days, starting June 2007 and ending October 2007. When colonized by aphids, the genet was marked with a label; the numbers of ramets on a genet were then counted along with the number of ramets colonized by aphids. Each aphid colony was estimated numerically (data not shown) and further inspected for aphid mummies. The aphid mummies formed by L. hirticornis are dark brownish in colour and readily distinguished from other parasitoid species attacking $M$. fuscoviride, in particular Aphidius tanacetarius Mackauer and Ephedrus spp. Haliday (Hymenoptera: Braconidae: Aphidiinae).

During subsequent visits, the fate of marked genets with aphid colonies was followed and any new genet colonization was marked and recorded. The dynamics of L. hirticornis are based on the occurrence of aphid mummies, which provide a basis for reliable estimates of the presence of the developing offspring of parasitoids. During visits, a maximum of 10 aphid mummies were sampled per genet. These were held in $1.5-\mathrm{ml}$ Eppendorf tubes for transport to the laboratory. Here, they were left to eclose and the sex of emerging adult wasps was determined under a stereo binocular microscope. Males and females from a single genet were stored separately in Eppendorf tubes in $100 \%$ ethanol at $4{ }^{\circ} \mathrm{C}$ before DNA extraction. The study continued for the 


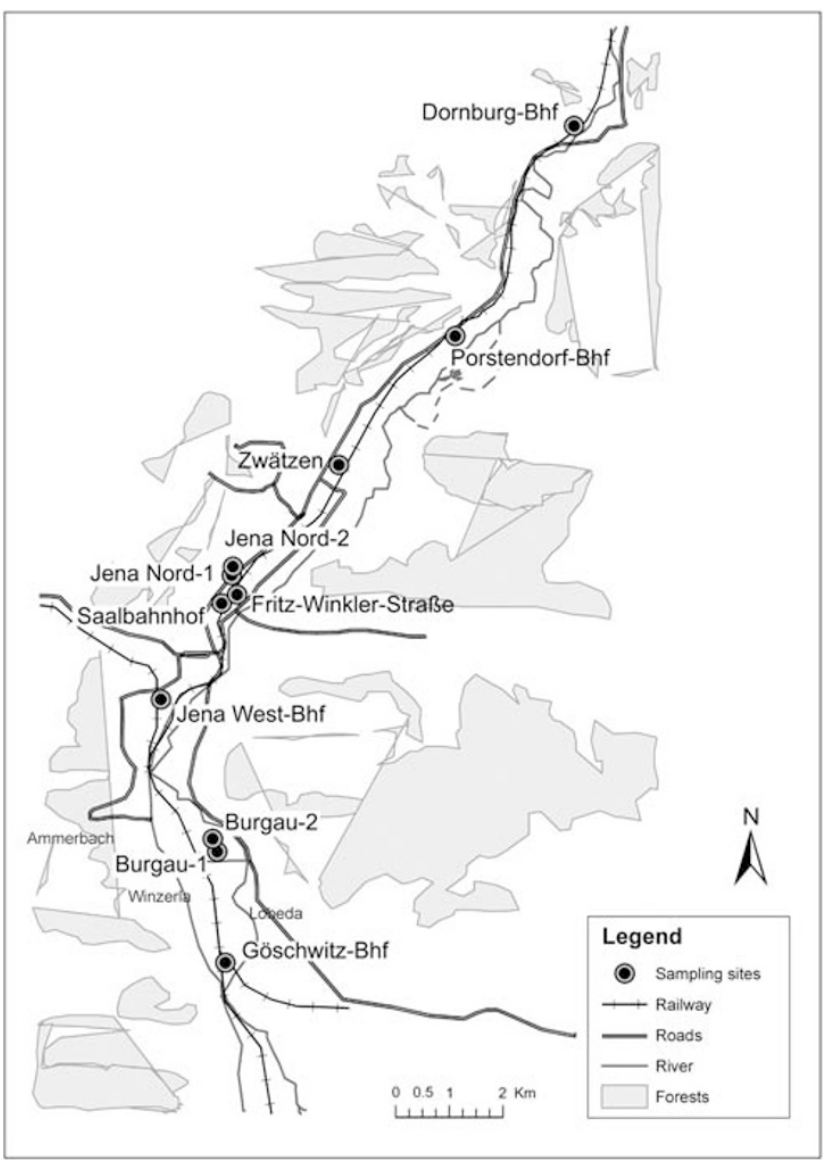

Figure 1 Schematic representation of the sampling sites of L. hirticornis. The closest distance was between Jena Nord-1 and Jena Nord-2, $217 \mathrm{~m}$ apart, and the furthest, $15106 \mathrm{~m}$, between Göschwitz-Bhf and Dornburg-Bhf.

entire growing season, until the shoots senesced and the aphid colonies collapsed.

\section{Microsatellite analysis}

For genetic analyses, only female parasitoids were used. In total, DNA from 321 female individuals (that is, between 25 and 30 wasps per site, Table 2) was extracted using the 'salting-out' method of Sunnucks and Hales (1996). Eleven polymorphic microsatellite loci were used as follows: nine (Lhirt 01, Lhirt02, Lhirt03, Lhirt04, Lhirt06, Lhirt08, Lhirt10, Lhirt15, Lhirt23) developed from L. hirticornis, and two others derived from published results for other Lysiphlebus species, that is, Lysi08 from $L$. fabarum (Marshall) and Lysi6b12 from L. testaceipes (Cresson) (see Nyabuga et al., 2009 for details and references therein).

\section{Genetic diversity in L. hirticornis populations}

Genetic diversity was quantified from observed heterozygosity $\left(H_{\mathrm{O}}\right)$ and the unbiased estimates of expected heterozygosity $\left(H_{\mathrm{E}}\right)$ calculated using ARLEQUIN (v.3.1; 2006, Excoffier et al., 2005). The number of alleles per locus $(A)$ and allelic richness was calculated using FSTAT version 2.9.3.2 (Goudet, 2002). Values for allelic richness were subjected to analysis of variance in SPSS v. 16 (SPSS, 2007) to determine differences in population genetic diversity. Within-sample deviation from HardyWeinberg equilibrium (HWE) was tested in GENEPOP (V.4.0; Raymond and Rousset, 1995) under the dual null hypotheses of both heterozygote excess and deficiency for individual loci as well as over all loci. An estimate of private (unique) allele frequency was also performed using GENEPOP as described by Barton and Slatkin (1986).

The hierarchical partitioning of the genetic variance was calculated with ARLEQUIN using an analysis of molecular variance framework with 11 populations (Weir and Cockerham, 1984; Excoffier et al., 1992). Pairwise and global $F_{\mathrm{ST}}$ according to Weir and Cockerham (1984) were calculated in ARLEQUIN. Absolute differentiation $\left(D_{\mathrm{ST}}\right.$, the proportion of gene diversity present among populations), relative differentiation $\left(G_{\mathrm{ST}}\right.$, a measure of genetic differentiation estimated as the gene diversity between populations relative to the combined population) (Nei, 1973) and actual differentiation (D) (Jost, 2008) were calculated using SMOGD, version 1.2.5 (Crawford, 2009). In brief, $D_{\mathrm{ST}}$ is the difference between total heterozygosity $\left(H_{\mathrm{T}}\right.$, heterozygosity of the pooled subpopulations) and the mean within-subpopulation heterozygosity $\left(H_{\mathrm{S}}\right.$, the mean heterozygosity of the individual subpopulations): $D_{\mathrm{ST}}=H_{\mathrm{T}}-H_{\mathrm{S}}$. Nei (1973) called $D_{\mathrm{ST}}$ a measure of absolute differentiation, and he divided this by total diversity $\left(H_{\mathrm{T}}\right)$ to obtain what he termed the relative differentiation, $G_{\mathrm{ST}}: G_{\mathrm{ST}}=D_{\mathrm{ST}} / H_{\mathrm{T}}$. Nei's $G_{\mathrm{ST}}$ is equivalent to Wright's $F_{\mathrm{ST}}$ (Nei, 1973) and has a theoretical minimum of zero indicating no genetic divergence and a theoretical maximum of one indicating fixation for alternative alleles in different subpopulations. The observed maximum, however, is usually much less than one (see Wright, 1978 for further details). Actual differentiation, $D$ by Jost (2008) is calculated as: $D=$ $\left(J_{\mathrm{T}} / J_{\mathrm{S}}-1\right) /((1 / n)-1) \quad$ or $\quad\left(\left(\mathrm{H}_{\mathrm{T}}-\mathrm{H}_{\mathrm{S}}\right) /\left(1-\mathrm{H}_{\mathrm{S}}\right) /\left(1-\mathrm{H}_{\mathrm{S}}\right)\right)$ $(n /(n-1))$, where $J_{\mathrm{T}}$ is the gene identity of the pooled subpopulations, $J_{S}$ is the gene identity within subpopulation and $n$ the number of subpopulations. Values of $D$ range between zero (no genetic differentiation) to one (subpopulation fixation). Jost (2008) argued that $G_{S T}$ and its relatives did not rank species correctly in terms of differentiation because they used expected heterozygosity in their calculations and discusses a number of shortcomings. Thus he proposed that actual differentiation $(D)$ was a better estimate (see Jost, 2008 for details). In spite of the shortcomings of $F_{\mathrm{ST}}$ and its relatives, nevertheless, the index continues to prove useful in many population genetic studies, hence its calculation here.

For each parasitoid population, the proportion of unique genotypes $D^{*}$ was calculated as the number of genotypes present only in that population divided by the total number of parasitoid wasps analysed (Hunter, 1993).

\section{Bottleneck analysis}

A graphical technique was used to test for severe reductions in population size, that is, bottlenecks (Luikart et al., 1998). The method 'allele distortion by graphical technique' involves comparing the distribution of allele frequencies observed in a population suspected of having gone through a bottleneck with the distribution expected in a population not having done so. For 
selectively neutral loci in a natural population, allele number and frequency distribution result from a dynamic equilibrium between mutation and genetic drift. The graphical method groups alleles from a sample of at least five polymorphic loci into ten allele frequency classes (0.001-0.100, $0.101-0.200,0.201-0.300$, and so on) and then plots a frequency histogram. Populations that have not gone through a bottleneck and are near mutation-drift equilibrium for selectively neutral loci are expected to have a large proportion of alleles at low frequency allele classes (Luikart et al., 1998). Low-frequency allele classes are defined as those between $0-0.1$; high-frequency allele classes between 0.901-1.00; and the eight intermediate classes between 0.101 and 0.900 .

The Garza-Williamson index (G-W index; Garza and Williamson, 2001) was also used to estimate bottlenecks. The index is calculated as: $\mathrm{G}-\mathrm{W}=k / R+1$, where $k$ is the number of alleles at a given locus in a population sample and $R$ is the allelic range of that particular locus. The statistic has a very low value in a population that has passed through a bottleneck and is close to unity in a stationary population.

\section{IBD}

The measure of population differentiation $F_{\mathrm{ST}} /\left(1-F_{\mathrm{ST}}\right)$ developed by Rousset (1997) was used to test for IBD. $F_{\mathrm{ST}}$ values were used to compute Rousset's (1997) genetic distance, and thereafter all IBD calculations were computed using an application program, Isolation by Distance Web Service (IBDWS Version 3.15; Jensen et al., 2005). IBDWS assesses whether there is a statistically significant relationship between the genetic distance (or similarity) matrix and the comparable matrix of geographical distances using Mantel tests (Bohonak, 2002).

\section{Relatedness and assignment of individual genotypes to populations for philopatry analysis}

Population assignment was performed using logarithm of likelihood measures calculated in ARLEQUIN. To assign a multilocus genotype (MLG) to a population, an individual's allele frequencies are estimated at each locus. The genotypes' expected frequency at each locus in its sampled population is determined and the value is multiplied across all loci and the product logarithm transformed. The same calculations to estimate the genotypes' frequency in other putative source populations are repeated and the MLG assigned to the population in which it has the highest logarithm likelihood (that is, greatest probability) of occurrence (Paetkau et al., 1995; Waser and Strobeck, 1998).

Estimation of relatedness was performed using the program ML-RELATE (Kalinowski et al., 2006). Each individual in each population was related to all other individuals and the maximum likelihood values obtained ( $=102720$ pairwise relatedness comparisons) were categorized as follows: $0=$ unrelated; $0.0001-$ $0.25=$ weakly related; $0.2501-0.5000=$ moderately related; $0.5001-0.9999=$ highly related and $1.0=$ fully related Within- and between-population comparisons were then performed using the category frequencies.

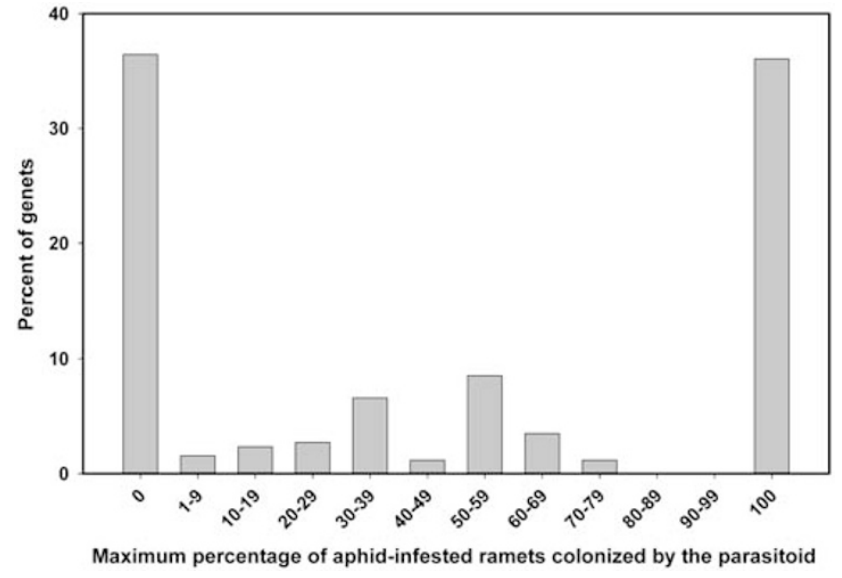

Figure 2 Maximum L. hirticornis occupation of aphid colonies within genets. The graph shows the maximum percentage of aphidinfested ramets per genet that also had parasitoids $(N=258$ genets with aphids). For each genet, the maximum derives from the 12 inspections during the season.

\section{Field data and correlations}

Field data means and all Pearson's correlations were performed by SPSS version 16 for windows (SPSS, 2007). The significance level was set at $\alpha=0.05$.

\section{Results}

\section{L. hirticornis population ecology}

Parasitoid dynamics: Mummified aphids were found at all sites, indicating the presence of L. hirticornis. After pooling data of genets with aphids from all sites over the entire season; $36 \%$ of the genets were not colonized by parasitoids, $36 \%$ of the genets had $100 \%$ of all aphid colonies colonized by the parasitoid, and on the remaining $28 \%$ of genets, between 1 and $79 \%$ of their aphid colonized ramets were colonized by the parasitoid (Figure 2). The percentage of genets with aphids colonized by the parasitoid increased from $6 \%$ in early June (4-13) to $41.1 \%$ in mid-July (4-13), and thereafter began to steadily decline to about $3 \%$ by the end of the season (30 October). Within genets colonized by both aphid and parasitoid, the mean percentage of ramets with aphids and colonized by parasitoids increased from $2 \%$ in June (4-13) to $40 \%$ by the end of the season (30 October), thus showing the infection to have spread locally. Within sites, the percentage of aphid-infested genets with mummified aphids on all aphid-infested ramets ranged from $12 \%$ at Porstendorf-Bhf to $69 \%$ at Fritz-Winkler-Straße (Supplementary Appendix 1). A total of 1796 L. hirticornis parasitoids emerged from the mummies collected; of these, 553 were males, an average sex ratio of 0.31 (sex ratio is calculated as the number of males to total parasitoids). Generally, female biased sex ratios were calculated on all sites and ranged from 0.17 in Porstendorf-Bhf to 0.49 in Saalbahnhof (Table 2).

\section{Microsatellite overall diversity}

The observed number of alleles ranged from 2 at locus Lysi08 and Lhirt08 to 21 at Lhirt01 and Lhirt04, mean $=8.0$ (s.d. $=6.67)$. Overall expected heterozygosity ranged from 0.186 at Lysi6b12 to 0.858 at Lhirt01 (Table 1). Private alleles were recorded at 5 of the 11 loci tested 
(Supplementary Appendix 2). Allelic size distributions varied among loci resulting in differences in their overall variances, for example, the variance of Lhirt04 was 63 times greater than that of Lysi08 (Table 1). A few loci showed disjunct allelic size distributions in which size classes were separated by several base pairs. This was particularly so at locus Lhirt04, which had an allelic size range of 160-286 bp, but no alleles were found between 160-244 bp; locus Lhirt15 (allele size range 300-330 bp) had no alleles between 300 and 320; and locus Lhirt01 (allele size range 182-270 bp) had gaps between 182-192, 196-216 and 238-252 bp.

\section{Within-population genetic diversity}

The mean number of alleles per locus for each population ranged from 2.9 (Zwätzen) to 4.4 (Burgau-2) (Table 2). Allelic frequencies ranged from $2 \%$ at locus Lysi08 in Burgau-1 to $100 \%$ (fixation) at locus Lysi6b12 in Fritz-Winkler-Straße (Supplementary Appendix 2). The observed differences in allelic richness among populations sampled were not significant $\left(F_{10,100}=51.03\right.$, $P=0.085)$.

Of the MLGs observed, 310 were found for the 321 parasitoids analysed at the 11 loci. Ten MLGs were repeated (multiple repeats): nine were duplicated, and one was found three times. The repeated MLGs were sampled from ten tansy genets from various sites (four

Table 1 Allelic richness and allelic size variance for the 11 microsatellite loci used in population analysis

\begin{tabular}{lccc}
\hline $\begin{array}{l}\text { Microsatellite } \\
\text { loci }\end{array}$ & $\begin{array}{c}\text { Number of } \\
\text { alleles }\end{array}$ & $\begin{array}{c}\text { Allelic size variance } \\
(\mathrm{bp})\end{array}$ & $\begin{array}{c}\text { Expected } \\
\text { heterozygosity }\end{array}$ \\
\hline Lhirt01 & 21 & 88 & 0.858 \\
Lhirt02 & 8 & 14 & 0.447 \\
Lhirt03 & 10 & 40 & 0.815 \\
Lhirt04 & 21 & 126 & 0.854 \\
Lhirt06 & 9 & 24 & 0.612 \\
Lhirt08 & 2 & 3 & 0.336 \\
Lhirt10 & 3 & 5 & 0.591 \\
Lhirt15 & 4 & 30 & 0.417 \\
Lhirt23 & 5 & 28 & 0.640 \\
Lysi08 & 2 & 2 & 0.202 \\
Lysi6b12 & 3 & 8 & 0.186 \\
\hline
\end{tabular}

from Zwätzen, two from Burgau-1, and one each from Burgau-2, Jena West-Bhf and Fritz-Winkler-Straße). The proportion of unique genotypes $\left(D^{*}\right)$ found per population ranged from 0.87 (Zwätzen) to 1.0 (populations Jena Nord-1, Göschwitz-Bhf, Saalbahnhof, Jena Nord-2 and Porstendorf-Bhf; Table 2). The number of genets from which parasitoids were collected and the proportion of unique genotypes were not correlated $(r=0.43$, $\left.F_{1,10}=2.01, P=0.190\right)$. The number of alleles per population and the number of MLGs were marginally correlated $\left(r=0.61, F_{1,10}=5.35, P=0.046\right)$; and the number of genets from which the parasitoids were collected was correlated with the number of alleles per population $\left(r=0.61, F_{1,10}=5.44, P=0.045\right)$. The correlation between the number of alleles per population and number of parasitoids genotyped was not significant $(r=0.03$, $F_{1,10}=0.01, P=0.938$ ).

Of the 121 Fisher's exact tests performed (11 populations at 11 loci) to measure deviations from HWE, $74(61.2 \%)$ were significant $(P<0.05$, Table 2$)$; moreover, significant heterozygote deficits were found in 65 of the $74(87.8 \%)$ significant deviations. Only one test showed significant heterozygote excess (Saalbahnhof at locus Lhirt06; $P=0.029$, s.e. $=0.002$ ) Over all loci, all the 11 populations had significantly positive $F_{I S}$ values (Table 2). $H_{\mathrm{O}}$ ranged from 0.367 in subpopulation Jena Nord-2 to 0.170 in Burgau-2, mean $=0.28 \pm 0.18$ (s.d.); $H_{\mathrm{E}}$ from 0.533 in Jena Nord-2 to 0.423 in Burgau-2, mean $=0.54 \pm 0.23$ (s.d.).

\section{Population differentiation and IBD}

In all, 18 out of the total 88 alleles were private (Supplementary Appendix 2). There were six such alleles at locus Lhirt01 distributed among six populations and eight at locus Lhirt04, distributed as follows: three in Burgau-1, two in Saalbahnhof, two in Jena Nord-2 and one in Jena West-Bhf. Two private alleles at locus Lhirt06 were found in populations Jena Nord-1 and Saalbahnhof. A single private allele each at loci Lhirt15 and Lysi6b12 was recorded in populations at Fritz-Winkler-Straße and Saalbahnhof, respectively. A mean frequency of 0.097 private alleles was calculated. Analysis of molecular variance in ARLEQUIN revealed that $15 \%$ of the

Table 2 Details of population genetic diversity in L. hirticornis samples at the 11 microsatellite loci

\begin{tabular}{lrccccccccccccccccc}
\hline & $\mathrm{N}_{\text {genets }}$ & Sex ratio & $\mathrm{N}_{\text {parasitoids }}$ & $\mathrm{N}_{\text {genotypes }}$ & $\mathrm{D}^{*}$ & $M N A$ (s.d.) & $\mathrm{H}_{E}$ (s.d.) & $\mathrm{H}_{O}$ (s.d.) & $\mathrm{F}_{I S}$ & $H W$ & $H D$ & $H E$ & $\mathrm{G}_{S T}$ & $\mathrm{D}_{S T}$ & $\mathrm{D}$ \\
\hline Burgau-1 & 3 & 0.39 & 30 & 28 & 0.93 & $3.64(2.46)$ & $0.42(0.26)$ & $0.17(0.14)$ & $0.603^{* * *}$ & 8 & 8 & 0 & 0.5 & 0.416 & 0.784 \\
Burgau-2 & 17 & 0.35 & 30 & 29 & 0.97 & $4.36(2.46)$ & $0.46(0.20)$ & $0.25(0.13)$ & $0.473^{* * *}$ & 7 & 7 & 0 & 0.459 & 0.386 & 0.779 \\
Dornburg-Bhf & 2 & 0.39 & 30 & 29 & 0.97 & $3.91(2.07)$ & $0.44(0.24)$ & $0.25(0.12)$ & $0.442^{* * * *}$ & 7 & 5 & 0 & 0.494 & 0.419 & 0.807 \\
Fritz-Winkler-Straße & 5 & 0.42 & 25 & 28 & 0.93 & $3.91(2.43)$ & $0.51(0.27)$ & $0.27(0.26)$ & $0.473^{* * *}$ & 9 & 8 & 0 & 0.417 & 0.361 & 0.802 \\
Göschwitz-Bhf & 7 & 0.23 & 26 & 26 & 1 & $3.64(1.37)$ & $0.52(0.20)$ & $0.35(0.22)$ & $0.325^{* * *}$ & 8 & 6 & 0 & 0.393 & 0.33 & 0.740 \\
Jena Nord-1 & 11 & 0.26 & 30 & 30 & 1 & $4.00(2.22)$ & $0.48(0.22)$ & $0.29(0.18)$ & $0.414^{* * *}$ & 6 & 5 & 0 & 0.447 & 0.383 & 0.802 \\
Jena Nord-2 & 19 & 0.29 & 30 & 30 & 1 & $4.27(2.86)$ & $0.53(0.20)$ & $0.37(0.16)$ & $0.316^{* * *}$ & 5 & 4 & 0 & 0.381 & 0.323 & 0.748 \\
Jena West-Bhf & 11 & 0.27 & 30 & 29 & 0.97 & $4.09(2.31)$ & $0.44(0.26)$ & $0.25(0.14)$ & $0.426^{* * *}$ & 6 & 6 & 0 & 0.494 & 0.418 & 0.803 \\
Porstendorf-Bhf & 7 & 0.17 & 30 & 30 & 1 & $3.55(1.67)$ & $0.44(0.23)$ & $0.27(0.20)$ & $0.385^{* * *}$ & 6 & 5 & 0 & 0.487 & 0.406 & 0.782 \\
Saalbahnhof & 10 & 0.49 & 30 & 25 & 1 & $3.64(1.92)$ & $0.44(0.20)$ & $0.31(0.16)$ & $0.285^{* * *}$ & 4 & 5 & 1 & 0.495 & 0.418 & 0.801 \\
Zwätzen & 6 & 0.28 & 30 & 26 & 0.87 & $2.91(1.08)$ & $0.43(0.19)$ & $0.27(0.12)$ & $0.390^{* * *}$ & 8 & 6 & 0 & 0.493 & 0.416 & 0.799
\end{tabular}

Abbreviations: $D^{*}$, proportion of unique genotypes found per parasitoid population; $D$, actual differentiation (Jost, 2008); $D_{\mathrm{ST}}$, absolute differentiation (Nei, 1973); $F_{\mathrm{IS}}$, individual inbreeding coefficient in relation to subpopulation; $G_{\mathrm{ST}}$, relative differentiation (Nei, 1973); $\mathrm{HD}$, number of heterozygote deficits; $H_{\mathrm{E}}$, expected heterozygosity; $\mathrm{HE}$, number of heterozygote excesses; $H_{\mathrm{O}}$, observed heterozygosity; HW, number of loci showing significant deviations from HWE; MNA, mean number of alleles per locus.

For each population, number of genets $\left(N_{\text {genets }}\right)$ from which the sample ( $\left.N_{\text {parasitoids }}\right)$ were collected; sex ratio (males: total parasitoids); number of different multilocus genotypes deduced ( $\left.N_{\text {genotypes }}\right)$.

$* * * P<0.001$. 
variance was due to 'among-populations' differences, $35 \%$ due to 'among individuals within populations' and $50 \%$ due to 'within individuals' differences.

Absolute differentiation, $D_{\mathrm{ST}}$, ranged from 0.419 in Dornburg-Bhf to 0.323 in Jena Nord-2 (Table 2). Pairwise $F_{\text {ST }}$ values ranged from 0.065 (between Jena Nord-2 and Dornburg-Bhf) to 0.233 (between Zwätzen and Saalbahnhof; Table 3) and overall global $F_{\mathrm{ST}}$ was 0.148 . Relative differentiation, $G_{S T}$, showed Burgau-1 to be the most genetically differentiated parasitoid subpopulation (0.5) and Jena Nord-2 the least $(0.381)$ with mean $G_{S T}$ value of 0.46 . Actual differentiation, $D$, ranged from 0.74 in Göschwitz-Bhf to 0.807 in Dornburg-Bhf with a mean of 0.786 , indicating high levels of subpopulation differentiation (Table 2).

A Mantel test performed for matrix correlation between genetic distance $\left(F_{\mathrm{ST}} /\left(1-F_{\mathrm{ST}}\right)\right)$ and logarithm of geographical distance showed no IBD relationship $(Z=34.88, \quad r=-0.21$, intercept $=0.84 \pm 0.09$ s.e.; slope $=-0.18 \pm 0.03$ s.e.; $N=55$ : one-sided $P=0.86$ from 1000 randomizations)

\section{Bottlenecks}

Graphical distortions of allele frequencies showed that the majority of alleles in all populations studied to be in the low-frequency class (0.001-0.1) and therefore had an ordinary distribution of alleles, an indication that bottlenecks were not important in determining the population genetic makeup observed. In contrast, at the level of individual loci, the $G-W$ index revealed some low values $(<0.1)$ at three loci to a mean 0.636 at Lysi08 (Table 4). Over all loci, means ranged from 0.203 in population Burgau-1 to 0.264 in Burgau-2. At loci Lhirt08 and Lhirt10, all populations had a mean of 0.5 , and at locus Lysi08, ten populations had a mean of 0.667 . The low values of the $\mathrm{G}-\mathrm{W}$ index sometimes encountered ( 3 of 11 values; Table 4) suggests that these populations may have gone through bottlenecks at the various loci tested.

\section{Philopatry}

Population assignment using ARLEQUIN revealed that in 4 of the 11 populations studied (that is, Burgau-2, Jena Nord-1, Saalbahnhof and Zwätzen), all analysed individuals originated from their natal populations (Supplementary Appendix 3, Figures a-d). In the remaining subpopulations, most individuals were most likely to have originated from their natal patches, and only a few individuals (1-6) are predicted to have come from other subpopulations, for example, in Burgau-1, one individual may have originated from either Göschwitz-Bhf or Dornburg-Bhf, and in Fritz-Winkler-Straße, six individuals showed a high likelihood of having originated from other subpopulations (Supplementary Appendix 3, Figures e-k).

Analysis of within- and between-population relatedness using ML-RELATE showed that all populations had high proportions of full (1.0000), high (0.5001-0.9999) or moderate (0.2501-0.5000) degrees of relatedness within the population (Figure 3). In contrast, relatedness among populations was very low, as seen from the high proportions of unrelatedness (that is, zero) and low relatedness (0.0001-0.2500) values among pairs of individuals of different populations.

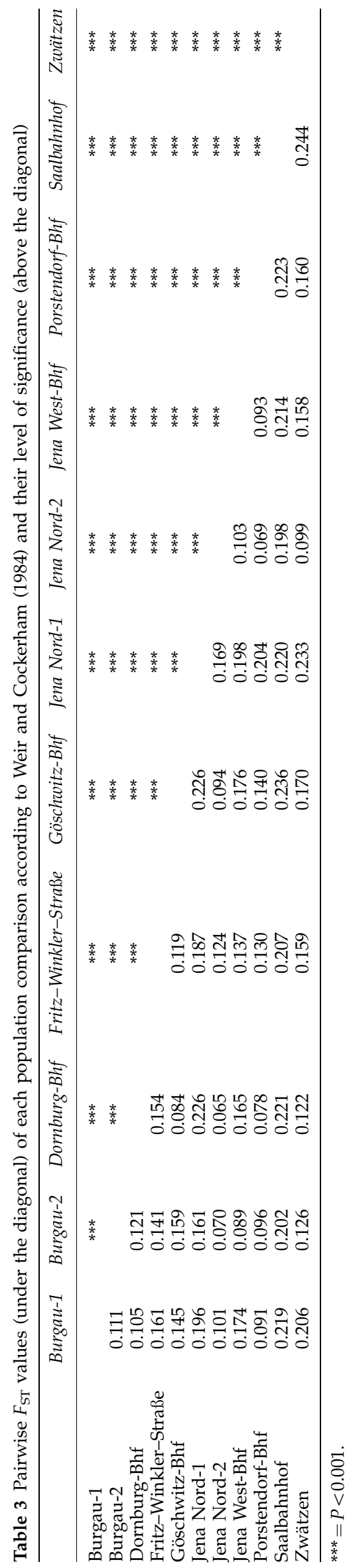


Table 4 Garza-Williamson indices per locus for each parasitoid population sample and means per locus for each population

\begin{tabular}{|c|c|c|c|c|c|c|c|c|c|c|c|c|}
\hline & Lhirt01 & Lhirt02 & Lhirt03 & Lhirt04 & Lhirt06 & Lhirt08 & Lhirt10 & Lhirt15 & Lhirt23 & Lysi08 & Lysi6b12 & $\begin{array}{c}\text { Mean G-W } \\
\text { index/population }\end{array}$ \\
\hline Burgau-1 & 0.056 & 0.133 & 0.171 & 0.071 & 0.120 & 0.500 & 0.500 & 0.065 & 0.172 & 0.333 & 0.111 & 0.203 \\
\hline Burgau-2 & 0.079 & 0.200 & 0.195 & 0.063 & 0.280 & 0.500 & 0.500 & 0.065 & 0.138 & 0.667 & 0.222 & 0.264 \\
\hline Dornburg-Bhf & 0.090 & 0.267 & 0.146 & 0.055 & 0.120 & 0.500 & 0.500 & 0.065 & 0.138 & 0.667 & 0.222 & 0.252 \\
\hline Fritz-Winkler-Straße & 0.112 & 0.267 & 0.146 & 0.047 & 0.120 & 0.500 & 0.500 & 0.097 & 0.103 & 0.667 & 0.111 & 0.243 \\
\hline Göschwitz-Bhf & 0.067 & 0.267 & 0.122 & 0.039 & 0.120 & 0.500 & 0.500 & 0.097 & 0.172 & 0.667 & 0.222 & 0.252 \\
\hline Jena Nord-1 & 0.090 & 0.200 & 0.146 & 0.063 & 0.160 & 0.500 & 0.500 & 0.065 & 0.138 & 0.667 & 0.222 & 0.250 \\
\hline Jena Nord-2 & 0.112 & 0.267 & 0.171 & 0.071 & 0.080 & 0.500 & 0.500 & 0.065 & 0.138 & 0.667 & 0.222 & 0.254 \\
\hline Jena West-Bhf & 0.101 & 0.267 & 0.122 & 0.063 & 0.160 & 0.500 & 0.500 & 0.065 & 0.138 & 0.667 & 0.222 & 0.255 \\
\hline Porstendorf-Bhf & 0.079 & 0.200 & 0.146 & 0.039 & 0.080 & 0.500 & 0.500 & 0.097 & 0.138 & 0.667 & 0.222 & 0.243 \\
\hline Saalbahnhof & 0.045 & 0.200 & 0.122 & 0.071 & 0.120 & 0.500 & 0.500 & 0.097 & 0.138 & 0.667 & 0.222 & 0.244 \\
\hline Zwätzen & 0.045 & 0.133 & 0.122 & 0.031 & 0.080 & 0.500 & 0.500 & 0.065 & 0.138 & 0.667 & 0.222 & 0.228 \\
\hline Mean G-W index/locus & 0.080 & 0.218 & 0.146 & 0.056 & 0.131 & 0.500 & 0.500 & 0.076 & 0.141 & 0.636 & 0.202 & 0.244 \\
\hline
\end{tabular}

Abbreviation: G-W index, Garza-Williamson index.

Values close to zero $=$ population or locus in bottleneck, whereas values close to one $=$ non-bottlenecked locus or population.

\section{Discussion}

This study highlights variations in levels of genetic diversity and differentiation among different L. hirticornis subpopulations (demes) comprising the metapopulation. Another main finding is the restricted level of aerial dispersal of the winged adult parasitoids and the lack of significant IBD as calculated from the molecular genetic data over the geographical scale studied. Population assignment measures indicate small amounts of genetic 'leakage' (gene flow) between populations, but with highly related individuals within sites compared with between sites, a characteristic of philopatric behaviour. Given the similar $F_{\mathrm{ST}}$ and heterozygosity results for L. hirticornis in this study to those of the earlier independent study of M. fuscoviride by Massonnet (2002), we suggest that L. hirticornis population genetic/ecological structuring and dynamics are directly influenced by the metapopulation genetic structure of its aphid host.

\section{Parasitoid metapopulation ecology in the field}

In the field study, winged adult L. hirticornis were observed to fly as well as walk between ramets within individual tansy genets harbouring aphid colonies. It is therefore highly probable that L. hirticornis flies, at least occasionally, to nearby genets and ramets. Our field results show that the number of ramets occupied by the parasitoid increased over time. Although cases of up to $100 \%$ aphid mummification on a ramet or genet were recorded, aphid colonies on some ramets and genets had no mummies throughout the season (Figure 2). These results thus confirm those of Weisser (2000) who also found that many genets colonized by aphids within a tansy stand were not attacked by the parasitoid, even though instances in which $100 \%$ of aphids in a ramet and / or nearby genet were parasitized. Rauch and Weisser (2007) similarly reported up to $100 \%$ rates of parasitism and noted that L. hirticornis was rarely found on plants on which it had not been released.

\section{Genetic variability and differentiation between populations} Genetic diversity for L. hirticornis in our study measured as observed heterozygosity was between $0.170-0.367$, and hence is in the range of other parasitoid populations studied using microsatellites, for example,
$H_{\mathrm{O}}=0.171-0.629$ in Neotypus melanocephalus Gmelin (Hymenoptera: Ichneumonidae) (Anton et al., 2007); 0.486-0.594 in Aphidius ervi Haliday (Hymenoptera: Braconidae: Aphidiinae) (Hufbauer et al., 2004); and 0.250-0.538 in Diaeretiella rapae M'Intosh (Hymenoptera: Braconidae: Aphidiinae) (Baker et al., 2003). Global population differentiation in L. hirticornis $\left(F_{\mathrm{ST}}=0.148\right)$ is slightly higher than in $N$. melanocephalus $\left(F_{\mathrm{ST}}=0.116\right)$ (Anton et al., 2007). Cotesia melitaearum Wilkinson (Hymenoptera: Braconidae) and $H$. horticola had $F_{\mathrm{ST}}$ values of 0.378 and 0.063 , respectively (Kankare et al., 2005). It seems, however, that L. hirticornis has dispersal behaviour similar to $N$. melanocephalus and C. melitaearum. Population assignment measures indicate small amounts of genetic leakage between the subpopulations and relatedness analysis shows that individuals within a site were highly related compared with between sites, findings that further support the view that L. hirticornis displays philopatric behaviour.

Compared with $G_{\mathrm{ST}}$ and $F_{\mathrm{ST}}$ values, actual differentiation $(D)$ values were higher and closer to unity, consistent with Jost (2008). The three measures indicated high levels of differentiation within populations and unlike Jost (2008), our results show that despite the presence of private alleles at a number of loci, L. hirticornis metapopulations shared many alleles.

With regard to population bottlenecks in our study, distorting allele frequencies and using graphical method (Luikart et al., 1998) to test for severe reduction in population size failed to show such restrictions. In contrast, the $\mathrm{G}-\mathrm{W}$ index gave low values (means $<0.3$ ), and as values close to unity are expected in populations that have not been through bottlenecks (Garza and Williamson, 2001), it is probable that bottlenecks are at least partially responsible for the population genetic structuring seen in L. hirticornis.

Departures from HWE, as found in all populations, may be due to either null alleles or violations of other assumptions inherent in fulfilling HW expectations. These include non-random mating, migration, selection, genetic drift, mutation and severe bottlenecks (discussed in preceding paragraph), and, in the case of the essentially neutral molecular markers used here, could be due to close linkage to areas under selection (hitchhiking). Failed amplifications were experienced in some individual parasitoids at some loci, even when the 


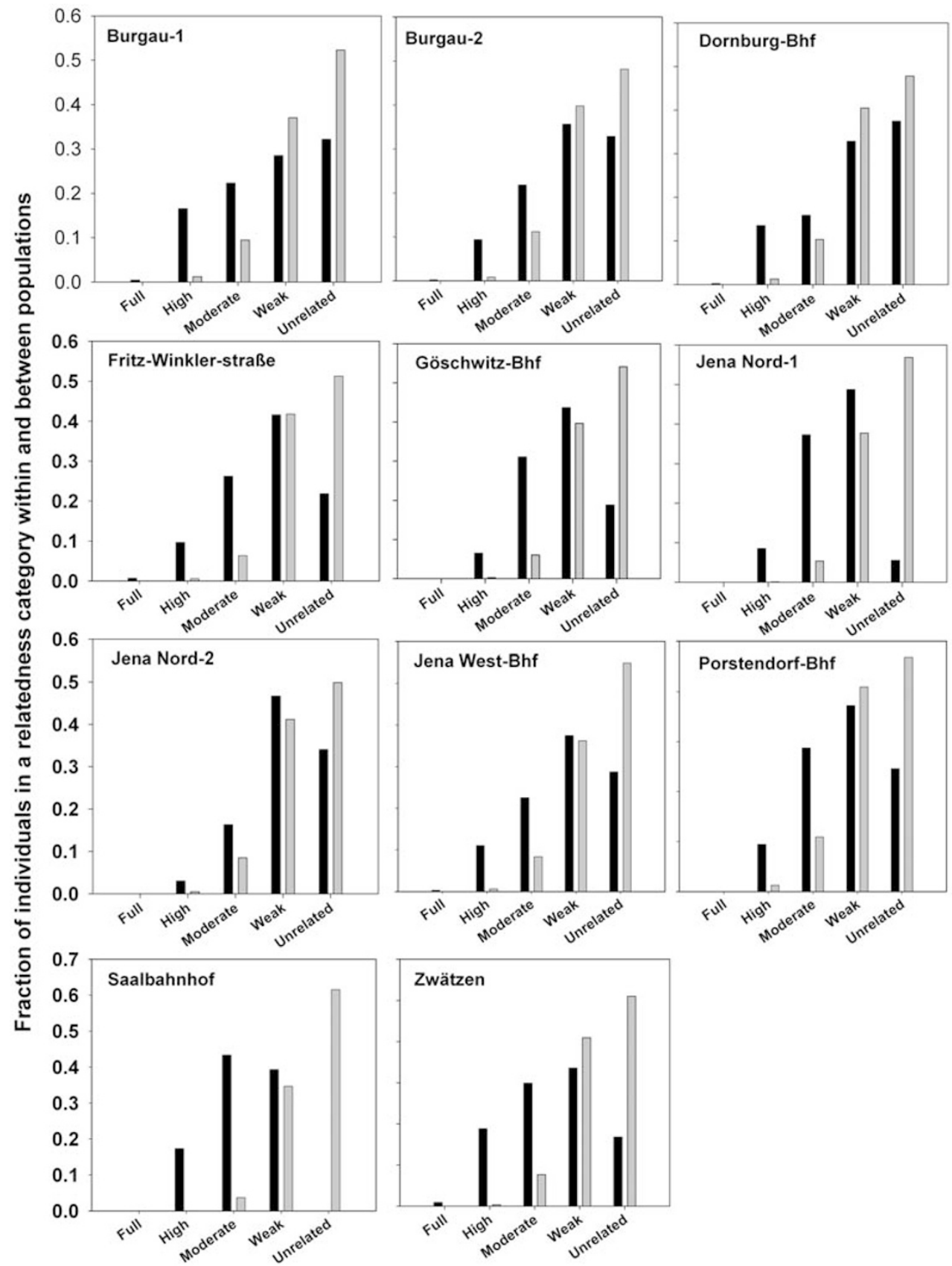

Figure 3 Within- and among-population relatedness of L. hirticornis individuals. For each of the 11 populations, pairwise levels of relatedness were calculated between individuals of the same population (within-population, full black bars) and between individuals of a population to individuals of other populations (among-population, light grey bars). Relatedness values were grouped as follows: $0=$ unrelated; $0.0001-$ $0.25=$ weakly related; $0.2501-0.5000=$ moderately related; $0.5001-0.9999=$ highly related and $1.0=$ fully related.

same individuals amplified satisfactorily at other loci. Nyabuga et al. (2009) report the possibility of null alleles at 6 of the 11 loci used in this study. It is unlikely, however, that null alleles were a main source of HW deviation because $88 \%$ of the male haploid parasitoids genotyped consistently gave the expected hemizygous genotype pattern at each of the 11 loci tested.

The $F_{\text {IS }}$ values were all positive (homozygote excess) in all subpopulations, indicating that non-random mating occurred. Private or unique alleles were also recorded for the different subpopulations at different loci and these results support the view that the parasitoid tends to undergo inbreeding at a very local level. The 10 repeated MLGs derived from parasitoid populations on aphids infesting a total of 10 tansy plants at 5 of the 11 sites examined. One site (Zwätzen) had four repeated MLGs deriving from four genets. This implies, importantly, that the unit of random mating is within a genet or a group of closely located genets, rather than at the level of the whole site.

Previous behavioural studies (see review by Völkl, 1997) established that a single L. hirticornis female oviposited many eggs (up to 30) within aggregated aphid colonies. Recent laboratory studies showed that 
L. hirticornis stayed on the natal patch for up to $4 \mathrm{~h}$ after emergence, and 52 out of 58 individuals ( 90\%) observed had matings on the natal patch (FN Nyabuga et al., unpublished), emphasizing the philopatric nature of $L$. hirticornis involving inbreeding.

\section{Comparison of $L$. hirticornis genetic differentiation with that of its aphid host}

Previous studies indicate that the haplodiploid nature of parasitoids (haploid males are produced from unfertilized eggs, diploid females from fertilized eggs) results in higher population genetic differentiation than in diploid organisms (Johannesen and Seitz, 2003; Anton et al., 2007). For example, Anton et al. (2007) reported higher $F_{\mathrm{ST}}$ values in the parasitoid $N$. melanocephalus $(0.115)$ compared with its host butterfly, M. nausithous (0.087). Using a simulation study, they found that only part of the higher genetic differentiation of the parasitoid can be attributed to haplodiploidy. Massonnet (2002), working on $M$. fuscoviride, reported an overall $F_{\mathrm{ST}}$ of 0.222, with values ranging from 0.066 to 0.230 in Germany (Bayreuth and Münster) and an even lower $F_{\mathrm{ST}}$ (0.148) for populations from Alsace in France. Populations of the aphid host M. fuscoviride (Massonnet, 2002) and L. hirticornis (this study; $F_{\mathrm{ST}}=0.148$ ) are thus both highly genetically differentiated, with no difference in $F_{\mathrm{ST}}$ values between the two species, the parasitoid at small spatial scale and the aphid on a larger geographical scale. Perhaps the failure to find higher $F_{\mathrm{ST}}$ values for the parasitoid compared with the host is due to the different sampling period or to the different sampling parameters, that is, localities and spatial levels. Massonnet (2002) reported $H_{\mathrm{E}}$ values ranging from 0.27 to 0.52 for M. fuscoviride, whereas our results ranged from 0.423 to 0.533 for L. hirticornis, essentially rather similar.

\section{Philopatry and survival in a metapopulation context}

The ecological and genetic data presented here, in addition to unpublished behavioural data (Nyabuga et al., in preparation), reveal a high level of L. hirticornis philopatry within $M$. fuscoviride colonies with little aerial dispersal between them. Thus, even though local extinctions of the aphid host are frequent, the parasitoid continues to exploit its host and contributes greatly to the demise of local aphid colonies, rather than spreading its genes over many aphid subpopulations, thereby (potentially at least) increasing genetic heterogeneity. In fact, this study system represents one of the few field examples involving metapopulations in which host colony extinction is directly due to natural enemy attack (Weisser, 2000). The low probability of the host population's survival raises the question as to why this particular behaviour involving philopatry has evolved, rather than a behaviour that would spread the risk, that is, an oviposition strategy that distributes eggs over several aphid colonies, as observed in many other parasitoids (Mackauer and Völkl, 1993). The parasitoid is apparently able to evade ant attacks by chemical mimicry, as found in Lysiphlebus cardui (Marshall) attacking the black bean aphid, Aphis fabae cirsiiacanthoidis Schrank on creeping thistle (Liepert and Dettner, 1996). We argue that a key trait of the parasitoid-the ability to use chemical mimicry to evade attack by aphidtending ants-explains this counter-intuitive behaviour.
As in many Lysiphlebus species, chemical signals on the epicuticular surface of L. hirticornis mimic those of its aphid host, hence making the parasitoid chemically undetectable to ants (Dettner and Liepert, 1994; Liepert, 1996). As a consequence, the parasitoid is able to exploit ant-tended aphid colonies and the offspring obtain protection by ants from attack by even higher trophic levels, that is, hymenopterous hyperparasitoids (Völkl, 1992). Ant-tended colonies also persist longer than untended ones. By concentrating ovipositions into already encountered ant-tended colonies, parasitoids apparently realize higher reproductive success than would otherwise be possible by costly dispersal and oviposition into several aphid colonies, many of which do not survive for very long (a mean survival time of 4.8 weeks has been reported for aphids at the genet level; Weisser, 2000).

In conclusion, this study, the first on an aphidparasitoid metapopulation system, shows that L. hirticornis has limited dispersal between resource patches or interpopulation movement coupled with philopatry and inbreeding. Genetic differentiation measurements clearly identified similarities between genetic structuring in L. hirticornis and its aphid host, M. fuscoviride.

\section{Conflict of interest}

The authors declare no conflict of interest.

\section{Acknowledgements}

FNN thank the Deutscher Akademischer Austausch Dienst (DAAD) for the financial support. We also thank Tobias Kaiser, Dr Astrid Groot and Dr Gerhard Schöfl of the Max Planck Institute for Chemical Ecology, Jena, for their intellectual support and advice on molecular techniques, and Professor Roger Butlin and two anonymous referees for their helpful comments on the paper.

\section{References}

Anton C, Zeisset I, Musche M, Durka W, Boomsma JJ, Settele J (2007). Population structure of a large blue butterfly and its specialist parasitoid in a fragmented landscape. Mol Ecol 16: 3828-3838.

Baker DA, Loxdale HD, Edwards OR (2003). Genetic variation and founder effects in the parasitoid wasp, Diaeretiella rapae (M'intosh) (Hymenoptera: Braconidae: Aphidiidae), affecting its potential as a biological control agent. Mol Ecol 12: 33033311.

Barton NH, Slatkin M (1986). A quasi-equilibrium theory of the distribution of rare alleles in a subdivided population. Heredity 56: 409-415.

Bay LK, Caley MJM, Crozier RH (2008). Meta-population structure in a coral reef fish demonstrated by genetic data on patterns of migration, extinction and re-colonisation. $B M C$ Evolutionary Biology 8: 248.

Bohonak AJ (2002). IBD (isolation by distance): a program for analyses of isolation by distance. Journal of Heredity 93 153-154.

Crawford NG (2009). SMOGD: software for measurement of genetic diversity (1.2.5). http://www.ngcrawford.com/ django/jost/.

Cronin JT, Reeve JD (2005). Host-parasitoid spatial ecology: a plea for a landscape-level synthesis. Proc R Soc B Biological Sci 272: 2225-2235. 
Dettner K, Liepert C (1994). Chemical mimicry and camouflage. Annu Rev Entomol 39: 129-154.

Excoffier L, Laval G, Schneider S (2005). Arlequin ver. 3.0: an integrated software package for population genetics data analysis. Evol Bioinformatics Online 1: 47-50.

Excoffier L, Smouse PE, Quattro JM (1992). Analysis of molecular variance inferred from metric distances among DNA haplotypes-application to human mitochondrialDNA restriction data. Genetics 131: 479-491.

Garza JC, Williamson EG (2001). Detection of reduction in population size using data from microsatellite loci. Mol Ecol 10: $305-318$.

Goudet J (2002). FSTAT, A program to estimate and test gene diversities and fixation indices (V.2.9.3.2). http://www2. unil.ch/popgen/softwares/fstat.htm.

Harrison S, Hastings A (1996). Genetic and evolutionary consequences of metapopulation structure. Trends Ecol Evol 11: $180-183$.

Hufbauer RA, Bogdanowicz SM, Harrison RG (2004). The population genetics of a biological control introduction: mitochondrial DNA and microsatellie variation in native and introduced populations of Aphidus ervi, a parisitoid wasp. Mol Ecol 13: 337-348.

Hunter CL (1993). Genotypic variation and clonal structure in coral populations with different disturbance histories. Evolution 47: 1213-1228.

Jensen JL, Bohonak AJ, Kelley ST (2005). Isolation by distance, web service. BMC Genetics 6: 13.

Johannesen J, Seitz A (2003). Comparative population genetic structures of the fruit fly Urophora cardui and its primary parasitoid Eurytoma robusta. Entomologia Experimentalis Et Applicata 108: 149-157.

Jost L (2008). GST and its relatives do not measure differentiation. Mol Ecol 17: 4015-4026.

Kalinowski ST, Wagner AP, Taper ML (2006). ML-RELATE: a computer program for maximum likelihood estimation of relatedness and relationship. Molecular Ecology Notes 6: 576-579.

Kankare M, van Nouhuys S, Gaggiotti O, Hanski I (2005). Metapopulation genetic structure of two coexisting parasitoids of the Glanville fritillary butterfly. Oecologia 143: 77-84.

Liepert C (1996). Chemische mimikry bei Blattlausparasitoiden der Gattung Lysiphlebus (Hymenoptera: Aphidiidae). University of Bayreuth: Bayreuth.

Liepert C, Dettner K (1996). Role of cuticular hydrocarbons of aphid parasitoids in their relationship to aphid-attending ants. J Chem Ecol 22: 695-707.

Luikart G, Allendorf FW, Cornuet JM, Sherwin WB (1998). Distortion of allele frequency distributions provides a test for recent population bottlenecks. Journal of Heredity 89: 238-247.

Mackauer M, Völkl W (1993). Regulation of aphid populations by Aphidiid wasps: does parasitoid foraging behavior or hyperparasitism limit impact? Oecologia 94: 339-350.

Massonnet B (2002). Metapopulation structure and population genetics of monophagous aphids on tansy (Tanacetun vulgare L.) $\mathrm{PhD}$ thesis University of Basel: Basel.

Massonnet B, Simon JC, Weisser WW (2002). Metapopulation structure of the specialized herbivore Macrosiphoniella tanacetaria (Homoptera, Aphididae). Mol Ecol 11: 2511-2521.
Mitich LW (1992). Intriguing world of weeds .35. Tansy. Weed Technol 6: 242-244.

Nei M (1973). Analysis of gene diversity in subdivided populations. Proc Natl Acad Sci USA 70: 3321-3323.

Nyabuga FN, Loxdale HD, Sharbel TF, Todd M, Weisser WW (2009). Microsatellites from Lysiphlebus hirticornis Mackauer (Hymenoptera: Braconidae), a specialist primary parasitoid attacking the specialist tansy aphid, Metopeurum fuscoviride Stroyan (Hemiptera: Aphididae). Molecular Ecology Resources 9: 931-934.

Orsini L, Corander J, Alasentie A, Hanski I (2008). Genetic spatial structure in a butterfly metapopulation correlates better with past than present demographic structure. Mol Ecol 17: 2629-2642.

Paetkau D, Calvert W, Stirling I, Strobeck C (1995). Microsatellite analysis of population structure in Canadian polar bears. Mol Ecol 4: 347-354.

Pannell JR, Charlesworth B (2000). Effects of metapopulation processes on measures of genetic diversity. Philos Transac $R$ Soc B Biological Sci 355: 1851-1864.

Purrenhage JL, Niewiarowski PH, Moore FBG (2009). Population structure of spotted salamanders (Ambystoma maculatum) in a fragmented landscape. Mol Ecol 18: 235-247.

Rauch G, Weisser WW (2007). Local and spatial dynamics of a host-parasitoid system in a field experiment. Basic and Applied Ecology 8: 89-95.

Raymond M, Rousset F (1995). Genepop (Version-4.0)—population genetics software for exact tests and ecumenicism. Journal of Heredity 86: 248-249.

Roslin T (2001). Spatial population structure in a patchily distributed beetle. Mol Ecol 10: 823-837.

Rousset F (1997). Genetic differentiation and estimation of gene flow from $F$-statistics under isolation by distance. Genetics 145: 1219-1228.

SPSS (2007). SPSS version 16 for Windows.

Starý P (1973). A review of the Aphidius species (Hymenoptera: Aphidiidae) of Europe. Annotationes Zoologicae et Botanicae (Bratislava) 85: 1-85.

Sunnucks P, Hales DF (1996). Numerous transposed sequences of mitochondrial cytochrome oxidase I-II in aphids of the genus Sitobion (Hemiptera: Aphididae). Mol Biol Evol 13: 510-524.

Völkl W (1997). Interactions between ants and aphid parasitoids: patterns and consequences for resource utilization. In: Dettner K, Bauer G and Völkl W (eds). Vertical Food Web Interactions. Springer: Berlin, pp 225-240.

Völkl W (1992). Aphids or their parasitoids-who actually benefits from ant-attendance. J Anim Ecol 61: 273-281.

Waser PM, Strobeck C (1998). Genetic signatures of interpopulation dispersal. Trends Ecol Evol 13: 43-44.

Weir BS, Cockerham CC (1984). Estimating F-statistics for the analysis of population-structure. Evolution 38: 1358-1370.

Weisser WW (2000). Metapopulation dynamics in an aphidparasitoid system. Entomologia Experimentalis Et Applicata 97: 83-92.

Wright S (1978). Evolution and Genetics of Populations: Variability Within and Among Natural Populations, Vol 4. University of Chicago press: Chicago.

Zheng C, Weisser WW, Harri SA, Ovaskainen O (2009). Hierarchical metapopulation dynamics of two aphid species on a shared host. American Naturalist 174: 331-341.

Supplementary Information accompanies the paper on Heredity website (http://www.nature.com/hdy) 